\title{
Prognostic value of HER-2/neu expression in epithelial ovarian cancer: a systematic review and meta-analysis
}

\author{
Kai Wang ${ }^{1, *}$, Chenan Guan ${ }^{3, *}$, Junhui $\mathbf{Y u}^{1,{ }^{1}}{ }$, Xiaoxiao Jin ${ }^{1}$, Ling Sun ${ }^{1}$, Lingzhi Zheng ${ }^{1}$, \\ Liang $\mathrm{Xia}^{2}$ and Yuquan Zhang ${ }^{4}$ \\ ${ }^{1}$ Department of Obstetrics and Gynecology, Taizhou Hospital of Zhejiang Province, Wenzhou Medical University, Linhai, \\ Zhejiang Province 317000, China \\ ${ }^{2}$ Department of Neurosurgery, Zhejiang Cancer Hospital, Hangzhou, Zhejiang Province 310022, China \\ ${ }^{3}$ Department of Kidney Internal Medicine, Taizhou Hospital of Zhejiang Province, Wenzhou Medical University, Linhai, \\ Zhejiang Province 317000, China \\ ${ }^{4}$ Department of Obstetrics and Gynecology, Affiliated Hospital of Nantong University, Nantong, Jiangsu Province 226001, \\ China \\ *These authors have contributed equally to this work \\ Correspondence to: Lingzhi Zheng, email: zhenglz123@126.com \\ Liang Xia, email: xialiang@zjcc.org.cn \\ Yuquan Zhang, email: m13362627683@163.com
}

Keywords: epithelial ovarian cancer, HER-2/neu, prognosis, meta-analysis

Received: December 02, $2016 \quad$ Accepted: July 26, $2017 \quad$ Published: September 06, 2017

Copyright: Wang et al. This is an open-access article distributed under the terms of the Creative Commons Attribution License 3.0 (CC BY 3.0), which permits unrestricted use, distribution, and reproduction in any medium, provided the original author and source are credited.

\section{ABSTRACT}

This study aimed to conduct a meta-analysis to investigate the association between human epidermal growth factor receptor 2 (HER-2/neu) expression and survival in patients with epithelial ovarian cancer (EOC). HER-2/neu is one of the most frequently studied molecular biological parameters in EOC, but its prognostic impact has not been fully assessed. PubMed and Embase were searched for studies that reported HER-2/neu expression and survival in patients with EOC. The primary outcome was overall survival (OS), and the secondary outcome was progressionfree survival (PFS). Hazard ratios (HRs) with 95\% confidence interval (CI) were determined using Mantel-Haenszel random-effects model. Publication bias was investigated using funnel plots and Egger's test. A total of 56 studies $(N=7212)$ were included in the analysis. The results showed that patients possessing HER-2/neu expression had significant disadvantages in OS ( $\mathrm{HR}=1.41 ; 95 \% \mathrm{CI}, 1.31$ to $1.51 ; P<$ $0.001)$ and PFS (HR = 1.38; 95\% CI, 1.23-1.56; $P<0.001)$. The trim-and-fill method, Copas model, and subgroup analyses stratified by the study characteristics confirmed the robustness of the results. The present study findings provided further indication that HER-2/neu expression in patients with EOC has an adverse impact on OS and PFS.

\section{INTRODUCTION}

Epithelial ovarian cancer (EOC) is considered as the second most common malignancy in women. It is the most frequently encountered cause of gynecological cancer death, and the fifth leading cause of cancer deaths in developing countries [1]. A total of 21,880 new cases of ovarian cancer were diagnosed in U.S. that resulted in 13,850 deaths during 2010 , with a cure rate of less than $40 \%$ [2]. The relatively poor prognosis of ovarian cancer is due to the lack of detection at an early stage and the limited application of effective therapies for the advanced-stage disease [3]. Established clinicopathological prognostic factors of EOC include World Health Organization (WHO) grade, residual tumor after primary surgery, age at diagnosis, performance status, histological characteristics, and tumor rupture during surgery. However these factors inadequately predicted the clinical outcomes of EOC [4]. Recently, several molecular markers that contribute significant roles in the formation and progression of EOC 
have been identified. According to the NCCN Ovarian Cancer Guideline Version 1.2016, BRCA1 or BRCA2 mutations are high risk carriers of ovarian cancer [5]. A UK based trial compared the multimodality screening of ovarian cancer with ultrasound and CA-125 versus either ultrasound alone and/or no screening and concluded that the former was more effective in the detection of earlystage cancer [6]. Despite this evidence, the molecular mechanisms contributing to its aggressiveness are not fully understood. Therefore, the identification of novel prognostic markers has a substantial clinical impact on the future management of EOC.

P53 is a tumor suppressor protein that is widely studied as a prognostic factor of EOC. In addition, the EGFR and HER-2/neu proteins are considered prognostic factors of EOC. These markers have been used in cancer therapy. HER-2 (p185, HER-2/neu, ErbB-2) is a tyrosine kinase receptor that is located in the cell membrane and is $185 \mathrm{kDa}$ in size. TheHER-2 receptor regulates a multitude of biological processes such as cell proliferation, apoptosis, survival, migration, and differentiation [7].

Slamon investigated the association of HER2 overexpression with the survival of EOC patients [8]. The majority of the subsequent studies further support the hypothesis that HER-2/neu overexpression is an adverse prognostic factor for the survival of patients with EOC [914]. However, potential heterogeneity existed among these studies, and hence the prognostic value of the elevated expression of HER-2/neu was not investigated.

Therefore, this systematic review and meta-analysis study was conducted in order to comprehensively combine the available study findings on the effects of HER-2/neu expression on the EOC patient survival.

\section{RESULTS}

\section{Study selection procedure}

The study selection procedure was shown in Figure 1. The initial literature search indicated a total of 2,127 studies. Of these, 437 studies were excluded because of overlapping data sets. Subsequently, 1,570 studies were ruled out by reading the title and/or abstract. An additional 4 relevant studies were included from the reference lists. The full text reading of the remaining studies resulted in the exclusion of 60 additional studies ( 9 studies shared an identical population; 34 studies had no relevant outcomes; 6 studies were with small sample size and 11 studies were letters, comments, or correspondence). Moreover, 8 studies were ruled out due to insufficient data. Finally, 56 studies were included with sufficient data for extraction.

\section{Study characteristics}

The study characteristics are highlighted in Table 1. Finally, a total of 56 studies were included: 8 studies from
North America, 7 from Asia, and 36 from Europe [8, 9, 11-64]. These studies were published between the years 1989 and 2015. A total of 7,212 patients were included in the meta-analysis study with a median sample size of 40-783. The median follow-up period ranged from 33 to 213 months. The parameters overall survival (OS) and progression-free survival (PFS) were extracted from 49 and 22 studies, respectively.

\section{HER-2/neu expression and OS}

Combined analysis showed that the comparison of the patients without HER-2/neu expression with patients possessing HER-2/neu expression always indicated a significant $\mathrm{OS}$ disadvantage $(\mathrm{HR}=1.41 ; 95 \% \mathrm{CI}, 1.31$ to $1.51 ; \mathrm{P}<0.001$, Table 2, Figure 2). A total of 51 cases were used for this analysis Subgroup analyses were carried out on the basis of the study origin, sample size, followup period, patient's age, detection assay, survival analysis, WHO grade, and chemotherapy regimen in order to overcome the heterogeneity between the studies $\left(I^{2}=39.8\right.$, $P=0.03)$. Funnel plots indicated significant publication and/or selection biases ( $P=0.018$ for OS; Figure 4A) as demonstrated by substantial asymmetry for HER-2/neu expression.

\section{HER-2/neu expression and PFS}

Combined analysis of the included studies showed that upon comparing patients devoid of HER-2/neu expression, the patients possessing HER-2/neu expression demonstrated a significant PFS disadvantage $(\mathrm{HR}=1.38$; 95\% CI, 1.23-1.56; $P<0.001$, Table 2, Figure 3). The data were derived from 23 studies. Statistically significant heterogeneity was observed between the studies $\left(I^{2}=32.9\right.$, $P=0.069$ ). The investigation of bias demonstrated funnel plot asymmetry for HER-2/neu expression, suggesting the potential of publication and/or selection biases $(P=0.037$ for PFS; Figure 4B).

\section{Subgroup analysis and meta-regression}

Subgroup analysis was employed in order to explore the heterogeneity causes for OS and PFS. The subgroups that exhibited similar effect sizes were divided into 9 predefined subgroups according to the variables study origin, sample size ( $\geq 100$ vs. $<100)$, follow-up period, patient's age, detection assay (IHC vs. Others). The detection assay was defined as 'Others' by experimental techniques namely, FISH ELISA and western blotting. The parameters survival analysis (multivariate vs. others), WHO grade (II- IV vs. I-IV) (I: tissue welldifferentiated containing many healthy looking cells; II, tissue moderately differentiated with more cells appear abnormal than healthy; III to IV, tissue poorly differentiated or undifferentiated with more cells appear abnormal and lack normal tissue structures), centers 
involved (single vs. Multiple) and chemotherapy (yes vs. no) were also included. The investigation of the effects caused to the survival of EOC patients by the various study characteristics was conducted by a meta-regression analysis in the subgroups based on HR estimates. For HRs of OS, no statistical significance was noted with regard to the differences in the treatment effects for the subgroups. The $P$ values of study origin, sample size $(\geq 100$ vs. $<100)$, follow-up period, patient age, detection assay (IHC vs. Others), survival analysis (multivariate vs. others), WHO grade (II- IV vs. I-IV), Centers involved (single vs. Multiple) and chemotherapy (yes vs. no) were 0.493, $0.666,0.656,0.823,0.290,0.871,0.057,0.155$ and 0.302 , respectively.

For HRs of PFS, no statistical significance was noted with regard to the differences in the treatment effects for the various subgroups. The $\mathrm{P}$ values for study origin, sample size, patient age, detection assay, survival analysis, WHO grade, Centers involved and chemotherapy were $0.623,0.990,0.319,0.411,0.549,0.414,0.958$ and 0.117 , respectively. However, follow-up period with a $\mathrm{P}$ value of 0.021 was identified as variance resource for PFS (Table 2).

\section{Sensitivity analysis}

The heterogeneity that was noted among the included studies with regard to OS was significantly different $\left(\mathrm{I}^{2}=49 \%\right)$. As shown in Figure 2, the studies conducted by Beckmann [24] and Felip et al [8] indicated results that were completely out of range with other studies and probably resulted in the heterogeneity. The Beckmann et al' study was published in French language, and the Felip et al' study was conducted in a small sample size. Following exclusion of these studies, the results suggested that patients possessing HER-2/neu expression demonstrated a significant PFS disadvantage over OS $(\mathrm{HR}=1.375,95 \%$ CI 1.281-1.476, $\mathrm{P}<0.0001)$ compared with patients without HER-2/neu expression. The remaining studies revealed no significant heterogeneity for the variable OS $\left(\mathrm{I}^{2}=25.1 \%\right)$.

\section{Publication bias}

Publication bias was evident for OS as demonstrated by funnel plot asymmetry (Figure 4A). A total of 15 missing studies are represented by hollow circles. This finding indicated publication bias, as demonstrated by the Begg's rank correlation test $(P=0.018)$. The adjusted summary HRs of random-effects was 1.31 (95\% CI, 1.171.46) and was derived by the trim-and-fill method (TFM) and 1.59 (95\% CI, 1.40-1.80). The Copas model confirmed that the analysis was in agreement with the primary analysis of the present study.

As regards PFS, the asymmetric plots were further observed (Figure 4B). TFM did not cause significant alteration to the data when 2 missing studies were included, while the adjusted random-effects summary HR was 1.29 (95\% CI, 1.08-1.53). This value was approximately the same with that noted for the summary HR(1.37) (95\% CI, 1.10-1.71) that was obtained using the Copas model (Supplementary Table 1).

\section{DISCUSSION}

The present study presented evidence regarding the application of HER-2/neu as a prognostic indicator

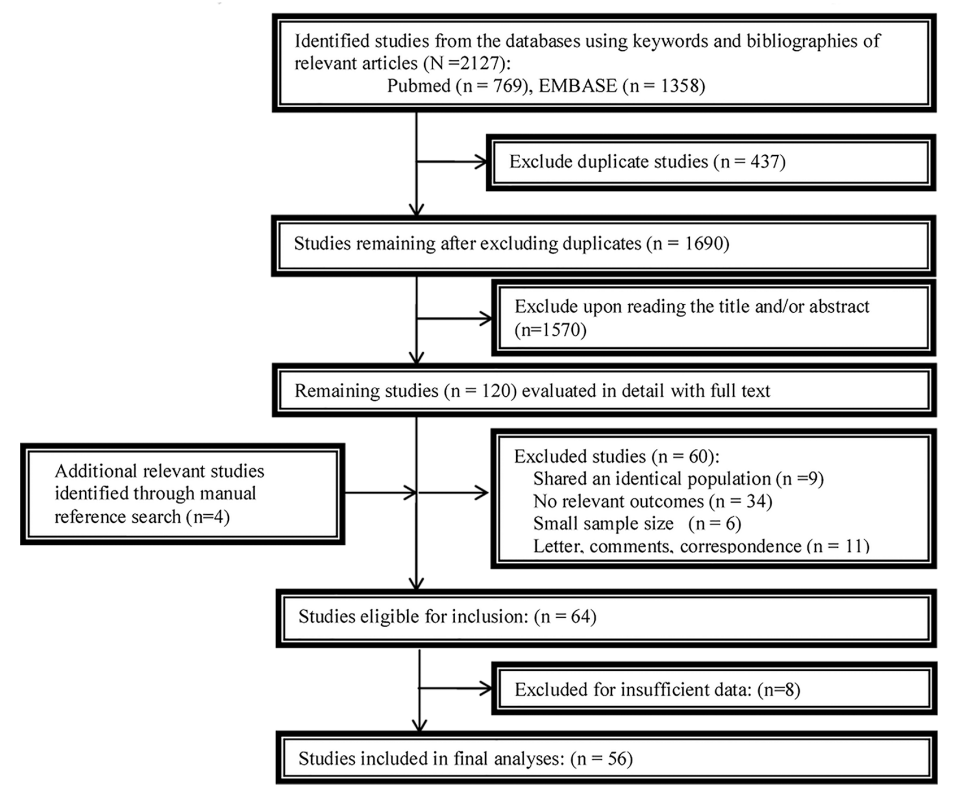

Figure 1: A flowchart of study selection. 
Table 1: Main characteristics of all the studies included in the meta-analysis

\begin{tabular}{|c|c|c|c|c|c|c|c|c|c|c|c|c|}
\hline Author & Year & Region & $\begin{array}{c}\text { Single or } \\
\text { multicenter }\end{array}$ & $\begin{array}{c}\text { No. of } \\
\text { patients }\end{array}$ & $\begin{array}{l}\text { mean } / \text { median } \\
\text { age }(y s)\end{array}$ & $\begin{array}{l}\text { WHO } \\
\text { stage }\end{array}$ & $\begin{array}{c}\text { expression } \\
\text { detection } \\
\text { method }\end{array}$ & outcomes & $\begin{array}{l}\text { Follow } \\
\text { up period } \\
\text { (years or } \\
\text { months or } \\
\text { day) }\end{array}$ & $\begin{array}{l}\text { Survival } \\
\text { analysis }\end{array}$ & Adjusted variables & Chemotherapy \\
\hline $\begin{array}{l}\text { Slamon et } \\
\text { al. [6] }\end{array}$ & 1989 & USA & single & 120 & NR & NR & IHC/South & OS & $\begin{array}{l}\text { median } 75.4 \\
\text { months }\end{array}$ & Univariate & - & - \\
\hline $\begin{array}{l}\text { Berchuck et } \\
\text { al. [7] }\end{array}$ & 1990 & USA & single & 73 & NR & III-IV & $\mathrm{IHC}$ & OS & NR & Univariate & - & - \\
\hline $\begin{array}{l}\text { Rubin et al. } \\
{[19]}\end{array}$ & 1993 & USA & single & 105 & mean $59(33-81)$ & III-IV & $\mathrm{IHC}$ & OS & $\begin{array}{l}\text { median } 34 \\
\text { months }\end{array}$ & multivariate & $\begin{array}{l}\text { Stage, grade, residual } \\
\text { tumor, histologicaltype, } \\
\text { Residual tumor }\end{array}$ & Platinum-based \\
\hline $\begin{array}{l}\text { Scambia et } \\
\text { al. [20] }\end{array}$ & 1993 & Italy & single & 94 & median 57(14-83) & III-IV & $\mathrm{IHC}$ & PFS & $\begin{array}{c}\text { median } 24 \\
\text { months }\end{array}$ & Univariate & $\begin{array}{l}\text { Age, Stage, grade, } \\
\text { Ascites, histological } \\
\text { type, Surgical } \\
\text { debulking, Response to } \\
\text { chemotherapy }\end{array}$ & Platinum-based \\
\hline $\begin{array}{l}\text { Singleton et } \\
\text { al. [21] }\end{array}$ & 1994 & USA & single & 56 & NR & I-IV & $\mathrm{IHC}$ & OS & NR & Univariate & $\begin{array}{l}\text { stage, histopathologic } \\
\text { subtype, grade }\end{array}$ & Platinum-based \\
\hline $\begin{array}{l}\text { Rubin et al. } \\
{[22]}\end{array}$ & 1994 & USA & single & 40 & mean 53(26-77) & I-II & $\mathrm{IHC}$ & PFS OS & $\begin{array}{c}\text { mean } 32 \\
\text { months }\end{array}$ & Univariate & $\begin{array}{l}\text { Stage, histological type, } \\
\text { grade }\end{array}$ & - \\
\hline $\begin{array}{l}\text { van Dam et } \\
\text { al. [23] }\end{array}$ & 1994 & Norwegian & single & 80 & NR & I-IV & $\mathrm{IHC}$ & os & NR & multivariate & $\begin{array}{c}\text { Age, stage, } \\
\text { histopathologicsubtype, } \\
\text { grade, residualdisease, } \\
\text { c-myc, c-ras, EGFR }\end{array}$ & Platinum-based \\
\hline $\begin{array}{l}\text { Felip et al. } \\
\text { [24] }\end{array}$ & 1995 & Spain & single & 72 & Mean 55 (19-74) & I-IV & $\mathrm{IHC}$ & OS & $\begin{array}{l}\text { median } 50 \\
\text { weeks }\end{array}$ & multivariate & $\begin{array}{l}\text { Age, Stage, histological } \\
\text { type, Residual tumor, } \\
\text { Chemotherapy }\end{array}$ & Ca.C \\
\hline $\begin{array}{l}\text { Fajac et al. } \\
{[25]}\end{array}$ & 1995 & France & single & 65 & mean 52 & I-IV & Southern Blot & OS & $\begin{array}{c}\text { median } 71 \\
\text { months }\end{array}$ & $\begin{array}{l}\text { univariate } \\
\text { and } \\
\text { multivariate }\end{array}$ & $\begin{array}{l}\text { Ag, Stage, grade, } \\
\text { histological type, } \\
\text { Residual tumor }\end{array}$ & Platinum-based \\
\hline $\begin{array}{l}\text { Medl et al. } \\
{[26]}\end{array}$ & 1995 & Austria & Multicenter & 196 & $\begin{array}{c}\text { median } 59.6(15- \\
88)\end{array}$ & I-IV & PCR & OS & $\begin{array}{c}\text { mean } 59 \\
\text { months }\end{array}$ & Univariate & $\begin{array}{l}\text { Stage, grade, Residual } \\
\text { tumor, Ascites, INT-2, ER }\end{array}$ & Platinum-based \\
\hline $\begin{array}{l}\text { Kaufmann et } \\
\text { al. [27] }\end{array}$ & 1995 & Germany & single & 77 & median $63(33-83)$ & I-IV & immunoassay & OS & $\begin{array}{l}\text { median } 19 \\
\text { months }\end{array}$ & multivariate & $\begin{array}{l}\text { age, stage, residual tumor, } \\
\text { Ca125, Chemotherapy }\end{array}$ & Platinum-based \\
\hline $\begin{array}{l}\text { van der Zee } \\
\text { et al. [28] }\end{array}$ & 1995 & Netherlands. & single & 89 & mean 50 & I-IV & $\mathrm{IHC}$ & PFS & NR & multivariate & $\begin{array}{c}\text { Age, Stage, grade, } \\
\text { Ascites, histological type, } \\
\text { P53, Chemotherapy }\end{array}$ & Platinum-based \\
\hline $\begin{array}{l}\text { Tanner et al. } \\
{[29]}\end{array}$ & 1996 & Germany & single & 79 & NR & I-IV & $\begin{array}{l}\text { S1 Nuclease } \\
\text { Assay }\end{array}$ & OS & NR & multivariate & $\begin{array}{c}\text { FIGO stage, } \\
\text { histopathologic subtype, } \\
\text { grade }\end{array}$ & P.C $/$ Ca.C \\
\hline $\begin{array}{l}\text { Beckmann et } \\
\text { al. [30] }\end{array}$ & 1996 & Germany. & single & 79 & mean52 (34-80) & I-IV & PCR & PFS OS & $\begin{array}{c}\text { median } 42 \\
\text { months }\end{array}$ & multivariate & $\begin{array}{l}\text { age, stage of disease, } \\
\text { grade, c-myc }\end{array}$ & Ca.C \\
\hline $\begin{array}{l}\text { Meden et } \\
\text { al. [9] }\end{array}$ & 1998 & Germany & single & 208 & mean 60 & I-IV & $\mathrm{IHC}$ & OS & $\begin{array}{c}\text { median } 24 \\
\text { months }\end{array}$ & Univariate & $\begin{array}{l}\text { Age, Stage, grade, } \\
\text { histological type, } \\
\text { chemotherapy }\end{array}$ & P.C/Ca.C \\
\hline $\begin{array}{l}\text { Hengstler et } \\
\text { al. [3] }\end{array}$ & 1999 & Germany & single & 77 & NR & I-IV & $\begin{array}{l}\text { S1 Nuclease } \\
\text { Assay }\end{array}$ & os & NR & multivariate & $\begin{array}{c}\text { Age, FIGO stage, } \\
\text { histopathologic subtype, } \\
\text { residual disease, } \\
\text { chemotherapy, grade, }\end{array}$ & Platinum-based \\
\hline $\begin{array}{l}\text { Wang ZR et } \\
\text { al. [32] }\end{array}$ & 1999 & USA & single & 40 & median $61(35-83)$ & II-IV & FISH & OS & $\begin{array}{l}\text { maximum } 56 \\
\text { months. }\end{array}$ & multivariate & $\begin{array}{l}\text { Age, Stage, grade, } \\
\text { histological type, c-myc }\end{array}$ & - \\
\hline $\begin{array}{l}\text { Davidson et } \\
\text { al. [10] }\end{array}$ & 2000 & Israel & single & 45 & median $56(30-84)$ & III-IV & $\mathrm{IHC}$ & OS & $\begin{array}{c}\text { Mean } 70 \\
\text { months }\end{array}$ & multivariate & $\begin{array}{l}\text { Age, histological type, } \\
\text { EGFR, E-cadherin, } \\
\text { Y-Catenin }\end{array}$ & - \\
\hline $\begin{array}{l}\text { Seki et al. } \\
{[33]}\end{array}$ & 2000 & Japan & single & 48 & NR & I-IV & PCR & OS & $\begin{array}{l}\text { maximum } \\
\text { 87months. }\end{array}$ & NR & $\begin{array}{l}\text { Age, Stage, grade, } \\
\text { histological type, tumor } \\
\text { size, Ascites, CA-125, } \\
\text { residual disease }\end{array}$ & - \\
\hline $\begin{array}{l}\text { Frutuoso et } \\
\text { al. [34] }\end{array}$ & 2001 & Portuguesa & single & 81 & mean $55.4 \pm 15$ & I-III & $\mathrm{IHC}$ & OS & NR & Univariate & $\begin{array}{c}\text { Age, Stage, grade, } \\
\text { Residual tumor, } \\
\text { histological type, } \mathrm{P} 53\end{array}$ & - \\
\hline $\begin{array}{l}\text { Skirnisdottir } \\
\text { et al. [35] }\end{array}$ & 2001 & Sweden & single & 106 & mean 60 & IA-IIC & $\mathrm{IHC}$ & OS & median87 & Univariate & $\begin{array}{l}\text { mean age, FIGO stage } \\
\text { and histopathologic } \\
\text { subtype, grade, EGFR }\end{array}$ & Platinum-based \\
\hline
\end{tabular}

(Continuned) 


\begin{tabular}{|c|c|c|c|c|c|c|c|c|c|c|c|c|}
\hline Author & Year & Region & $\begin{array}{c}\text { Single or } \\
\text { multicenter }\end{array}$ & $\begin{array}{l}\text { No. of } \\
\text { patients }\end{array}$ & $\begin{array}{c}\text { mean/median } \\
\text { age(ys) }\end{array}$ & $\begin{array}{l}\text { WHO } \\
\text { stage }\end{array}$ & $\begin{array}{c}\text { expression } \\
\text { detection } \\
\text { method }\end{array}$ & outcomes & $\begin{array}{l}\text { Follow } \\
\text { up period } \\
\text { (years or } \\
\text { months or } \\
\text { day) }\end{array}$ & $\begin{array}{l}\text { Survival } \\
\text { analysis }\end{array}$ & Adjusted variables & Chemotherapy \\
\hline Li et al. [36] & 2002 & china & single & 84 & median 49 & I-IV & $\mathrm{IHC}$ & OS & $\begin{array}{l}\text { median } 32.8 \\
\text { months }\end{array}$ & Univariate & $\begin{array}{c}\text { age, FIGO stage and } \\
\text { histopathologic subtype, } \\
\text { grade, P53, }\end{array}$ & - \\
\hline $\begin{array}{l}\text { Hogdall et al. } \\
\text { [37] }\end{array}$ & 2003 & Danish & Multicenter & 181 & median 60 & I-IV & $\mathrm{IHC}$ & $0 \mathrm{~s}$ & NR & multivariate & - & - \\
\hline $\begin{array}{l}\text { Tomic et al. } \\
{[38]}\end{array}$ & 2003 & Croatia & single & 80 & median 59 (34-79) & I-IV & $\mathrm{IHC}$ & OS & $\begin{array}{c}\text { median } \\
21 \text { month }\end{array}$ & multivariate & $\begin{array}{l}\text { age, stage, grade, p53, } \\
\mathrm{nm} 23 \text {, Vascular invasion }\end{array}$ & - \\
\hline $\begin{array}{l}\text { Camilleri- } \\
\text { Broet et al. } \\
{[39]}\end{array}$ & 2004 & Europe & Multicenter & 117 & median $59(18-70)$ & III-IV & $\mathrm{IHC}$ & OS PFS & $\begin{array}{l}\text { median of } 68 \\
\text { months }\end{array}$ & multivariate & $\begin{array}{l}\text { age, stage, Ascites, grade, } \\
\text { Tumor type, P53, BCL-2, } \\
\text { receptors }\end{array}$ & P.E.C \\
\hline $\begin{array}{l}\text { Nielsen et al. } \\
{[40]}\end{array}$ & 2004 & Denmark & Multicenter & 783 & median 58(13-91) & I-IV & $\mathrm{IHC}$ & OS & $\begin{array}{l}\text { median } 17.8 \\
\text { years }\end{array}$ & multivariate & $\begin{array}{c}\text { age, stage, grade, } \\
\text { histological type, P53, } \\
\text { EGFR }\end{array}$ & P.A.C $/$ Ca.C \\
\hline $\begin{array}{l}\text { Riener et al. } \\
{[41]}\end{array}$ & 2004 & Germany & Multicenter & 361 & median 57.6 & IIB-IV & $\mathrm{IHC}$ & OS, PFS & $\begin{array}{l}\text { median } 49.1 \\
\text { months }\end{array}$ & Univariate & $\begin{array}{l}\text { Stage, grade, histological } \\
\text { type, residual tumor, } \\
\text { lymph node metastasis }\end{array}$ & Platinum-based \\
\hline $\begin{array}{l}\text { Tanabe et al. } \\
\text { [42] }\end{array}$ & 2004 & Japan & Multicenter & 90 & NR & I-IV & $\mathrm{IHC}$ & OS & NR & Univariate & $\begin{array}{l}\text { Stage, histological type, } \\
\text { lymph node metasta-sis }\end{array}$ & - \\
\hline $\begin{array}{l}\text { Elie et al. } \\
\text { [11] }\end{array}$ & 2004 & France & multicentre & 93 & Median 58 & III-IV & $\mathrm{IHC}$ & PFS OS & $\begin{array}{c}\text { median } 69 \\
\text { months }\end{array}$ & multivariate & $\begin{array}{l}\text { Age, Stage, grade, } \\
\text { Ascites, histological type, } \\
\text { Residual tumour }\end{array}$ & Platinum-based \\
\hline $\begin{array}{l}\text { Chan et al. } \\
\text { [43] }\end{array}$ & 2004 & USA & multicentre & 46 & mean 41 years & III-IV & $\mathrm{IHC}$ & OS & $\begin{array}{l}\text { median } 37 \\
\text { months }\end{array}$ & multivariate & $\begin{array}{l}\text { Age, Stage, grade, } \\
\text { histological type }\end{array}$ & Platinum-based \\
\hline $\begin{array}{l}\text { Lee et al. } \\
\text { [44] }\end{array}$ & 2005 & British & single & 103 & mean 58(35-82) & III-IV & IHC/FISH & PFS & NR & Univariate & - & P.T \\
\hline $\begin{array}{l}\text { Verri et al. } \\
{[45]}\end{array}$ & 2005 & Italy & single & 194 & $\begin{array}{l}\text { Median } 57 \\
(25-90)\end{array}$ & I-IV & $\mathrm{IHC}$ & OS PFS & $\begin{array}{l}\text { median } 45 \\
\text { months }\end{array}$ & multivariate & $\begin{array}{c}\text { Age, stage, grade, } \\
\text { histologicaltype, residual } \\
\text { tumor }\end{array}$ & Platinum-based \\
\hline $\begin{array}{l}\text { Wang et al. } \\
{[46]}\end{array}$ & 2005 & Norway & single & 118 & median 60(38-81) & II-IV & $\mathrm{IHC}$ & PFS & $\begin{array}{l}\text { Median } 72 \\
\text { months }\end{array}$ & multivariate & $\begin{array}{c}\text { Age, Stage, grade, } \\
\text { histological type, residual } \\
\text { disease, ER }\end{array}$ & Platinum-based \\
\hline $\begin{array}{l}\text { Mayr et al. } \\
{[12]}\end{array}$ & 2006 & Germany & single & 163 & NR & I-IV & IHC/FISH & OS & NR & Univariate & $\begin{array}{l}\text { Age, Stage, histological } \\
\text { type }\end{array}$ & - \\
\hline $\begin{array}{l}\text { Surowiak et } \\
\text { al. [47] }\end{array}$ & 2006 & Poland & single & 43 & mean 51.0 & I-III & $\mathrm{IHC}$ & PFS OS & $\begin{array}{l}\text { Median } 24.6 \\
\text { months }\end{array}$ & multivariate & $\begin{array}{c}\text { Age, Stage, grade, } \\
\text { histological type, Clinical } \\
\text { response, CA-15, type of } \\
\text { chemotherapy }\end{array}$ & P.C/A.C.C \\
\hline $\begin{array}{l}\text { Castellvi et } \\
\text { al. [48] }\end{array}$ & 2006 & Spain & single & 75 & mean $55(20-87)$ & I-IV & $\mathrm{IHC}$ & OS & $\begin{array}{l}\text { Median } \\
\text { 31months }\end{array}$ & multivariate & $\begin{array}{c}\text { Age, stage, grade, } \\
\text { histologicaltype, residual } \\
\text { tumor }\end{array}$ & - \\
\hline $\begin{array}{l}\text { Brozek et al. } \\
\text { [49] }\end{array}$ & 2006 & Poland & single & 53 & NR & I-IV & FISH: & OS & NR & Univariate & $\begin{array}{l}\text { Age, Stage, grade, } \\
\text { histological type, CA- } \\
\text { 125, chemotherapy }\end{array}$ & Platinum-based \\
\hline $\begin{array}{l}\text { Steffensen et } \\
\text { al. [50] }\end{array}$ & 2007 & Danish & single & 160 & $\begin{array}{l}\text { median } 54.5 \\
(29-70)\end{array}$ & IIB-IV & IHC/FISH & OS & $\gg 10$ years & multivariate & $\begin{array}{l}\text { Age, stage, grade, } \\
\text { histological type, residual } \\
\text { tumor, COX2 expression }\end{array}$ & - \\
\hline $\begin{array}{l}\text { Sueblinvong } \\
\text { et al. [51] }\end{array}$ & 2007 & Thailand & Multicenter & 74 & $\begin{array}{c}\text { mean } 46.31(24- \\
67)\end{array}$ & I-II & IHC/FISH & OS, PFS & $\begin{array}{c}\text { median } 46 \\
\text { months }\end{array}$ & multivariate & $\begin{array}{c}\text { Age, Stage, grade, } \\
\text { Ascites, histological type, } \\
\text { capsular rupture, capsular } \\
\text { adherence }\end{array}$ & - \\
\hline $\begin{array}{l}\text { Tuefferd et } \\
\text { al. [52] }\end{array}$ & 2007 & France & Multicenter & 320 & median $58(25-77)$ & I-IV & IHC/FISH & OS PFS & NR & multivariate & $\begin{array}{l}\text { Age, Stage, grade, } \\
\text { Residual tumor, Ascites, } \\
\text { histological type, and } \\
\text { performance status }\end{array}$ & - \\
\hline $\begin{array}{l}\text { Sasaki et al. } \\
\text { [53] }\end{array}$ & 2007 & Japan & single & 141 & median 53(23-81) & I-IV & $\mathrm{IHC}$ & OS & NR & multivariate & $\begin{array}{c}\text { Age, Stage, grade, } \\
\text { histological type, residual } \\
\text { disease, Ascites, type of } \\
\text { chemotherapy }\end{array}$ & CAP \\
\hline $\begin{array}{l}\text { Malamou- } \\
\text { Mitsi et al. } \\
\text { [54] }\end{array}$ & 2007 & Greece & multicentre & 95 & mean 63 & IIc-IV & $\mathrm{IHC}$ & OS/PFS & $\begin{array}{l}\text { Median } 66 \\
\text { months }\end{array}$ & multivariate & $\begin{array}{c}\text { Age, Stage, grade, } \\
\text { histological type, residual } \\
\text { disease, P53, Bcl-2, type } \\
\text { of chemotherapy }\end{array}$ & P.C \\
\hline $\begin{array}{l}\text { Coronado } \\
\text { Martin et al. } \\
\text { [55] }\end{array}$ & 2007 & Spain & single & 124 & median 59.2 & I-IV & $\mathrm{IHC}$ & PFS OS & $\begin{array}{l}\text { Median } 62.3 \\
\text { months }\end{array}$ & multivariate & $\begin{array}{c}\text { Age, Stage, grade, } \\
\text { histological type, Cirugía } \\
\text { óptima, P53 }\end{array}$ & $\begin{array}{l}- \\
\text { (Continuned })\end{array}$ \\
\hline
\end{tabular}




\begin{tabular}{|c|c|c|c|c|c|c|c|c|c|c|c|c|}
\hline Author & Year & Region & $\begin{array}{l}\text { Single or } \\
\text { multicenter }\end{array}$ & $\begin{array}{c}\text { No. of } \\
\text { patients }\end{array}$ & $\begin{array}{l}\text { mean } / \text { median } \\
\text { age }(y s)\end{array}$ & $\begin{array}{l}\text { WHO } \\
\text { stage }\end{array}$ & $\begin{array}{c}\text { expression } \\
\text { detection } \\
\text { method }\end{array}$ & outcomes & $\begin{array}{l}\text { Follow } \\
\text { up period } \\
\text { (years or } \\
\text { months or } \\
\text { day) }\end{array}$ & $\begin{array}{c}\text { Survival } \\
\text { analysis }\end{array}$ & Adjusted variables & Chemotherapy \\
\hline $\begin{array}{l}\text { Pils et al. } \\
\text { [56] }\end{array}$ & 2007 & Austria & single & 128 & $\begin{array}{c}\text { mean } 58.6 \\
\text { (27.6-87.2 years) }\end{array}$ & I-IV & $\mathrm{IHC}$ & OS & $\begin{array}{l}\text { Median } 43.7 \\
\text { months }\end{array}$ & multivariate & $\begin{array}{l}\text { Age, Stage, grade, } \\
\text { histological }\end{array}$ & P.C \\
\hline $\begin{array}{l}\text { Tomsova et } \\
\text { al. [57] }\end{array}$ & 2008 & Europe & single & 116 & $\begin{array}{l}\text { median } 53( \\
27-82)\end{array}$ & I-IV & $\mathrm{IHC}$ & OS & $\begin{array}{l}\text { Median } 39 \\
\text { months }\end{array}$ & multivariate & $\begin{array}{l}\text {, Stage, grade, } \\
\text { histological type, type of } \\
\text { chemotherapy }\end{array}$ & Platinum-based \\
\hline $\begin{array}{l}\text { de Graeff et } \\
\text { al. [58] }\end{array}$ & 2008 & Netherlands & single & 232 & $\begin{array}{l}\text { median } 57.8 \\
\quad(22-90)\end{array}$ & I-IV & immunostain & OS PFS & NR & Univariate & $\begin{array}{c}\text { Age, Stage, grade, } \\
\text { Suboptimal debulking, } \\
\text { EGFR }\end{array}$ & Platinum-based \\
\hline $\begin{array}{l}\text { Garcia- } \\
\text { Velasco et al. } \\
\text { [59] }\end{array}$ & 2008 & Spain & single & 72 & median $57(28-82)$ & NA & $\mathrm{IHC}$ & OS PFS & $\begin{array}{l}\text { median } 33 \\
\text { months }\end{array}$ & Univariate & $\begin{array}{c}\text { Age, Stage, grade, } \\
\text { Residual disease, ER, } \\
\text { PR, P53, }\end{array}$ & P.C/P.C.C/Ca.C \\
\hline $\begin{array}{l}\text { Pfisterer et } \\
\text { al. [60] }\end{array}$ & 2009 & Germany & multicentre & 359 & mean 65 & IIB-IV & $\mathrm{IHC}$ & PFS OS & $\begin{array}{l}\text { median } 57.5 \\
\text { months }\end{array}$ & multivariate & $\begin{array}{l}\text { Age, Stage, grading, } \\
\text { histological type, residual } \\
\text { disease, tchemotherapy }\end{array}$ & Platinum-based \\
\hline $\begin{array}{l}\text { Farley et al. } \\
{[61]}\end{array}$ & 2009 & USA & multicentre & 133 & $\begin{array}{l}\text { median } 59.5 \\
(21.7-78.6)\end{array}$ & III-IV & ERBB2/CEP17 & PFS OS & NR & multivariate & $\begin{array}{c}\text { Age, Stage, grade, } \\
\text { histological type, residual } \\
\text { disease, Ascites, type of } \\
\text { chemotherapy }\end{array}$ & Platinum-based \\
\hline $\begin{array}{l}\text { Ferrero et al. } \\
{[62]}\end{array}$ & 2011 & Italy & single & 113 & median 62(25-80) & IIb-IV & $\mathrm{IHC}$ & OS & NR & Univariate & $\begin{array}{l}\text { Age, Stage, grade, } \\
\text { histological type, } \\
\text { postoperative residual } \\
\text { tumor, type of } \\
\text { chemotherapy }\end{array}$ & Platinum-based \\
\hline $\begin{array}{l}\text { Anglesio et } \\
\text { al. [63] }\end{array}$ & 2013 & $\begin{array}{l}\text { Alberta/ } \\
\text { AOCS/ } \\
\text { Mayo/ } \\
\text { Toronto }\end{array}$ & multicenter & 189 & mean $57.8(20-97)$ & I-IV & IHC/FISH/CIS & OS PFS & $\begin{array}{l}\text { median } 4.4 \\
\text { Years }\end{array}$ & multivariate & $\begin{array}{l}\text { age, stage, and debulking } \\
\text { statu, KRAS mutation } \\
\text { status }\end{array}$ & - \\
\hline $\begin{array}{l}\text { Chay et al. } \\
{[64]}\end{array}$ & 2013 & Singapore & multicenter & 133 & $\begin{array}{l}\text { median } 48.3 \\
(15.8-89.0)\end{array}$ & I-IV & DISH, IHC & OS PFS & NR & $\begin{array}{l}\text { Stage- } \\
\text { Adjusted } \\
\text { Analysis }\end{array}$ & $\begin{array}{c}\text { Age, Stage, Ethnic } \\
\text { group, differentiation, } \\
\text { Lymphovascular invasion }\end{array}$ & - \\
\hline $\begin{array}{l}\text { Demir et al. } \\
{[65]}\end{array}$ & 2014 & Turkey & single & 82 & median $54(24-80)$ & I-IV & $\mathrm{IHC}$ & OS & NR & multivariate & $\begin{array}{l}\text { Age, Stage, Residual } \\
\text { disease, Distant } \\
\text { Metastasis }\end{array}$ & - \\
\hline $\begin{array}{l}\text { de Toledo et } \\
\text { al. [66] }\end{array}$ & 2014 & Brazil & single & 152 & mean 55.2 & I-IV & $\mathrm{IHC}$ & OS, PFS & $\begin{array}{l}\text { mean } 43.6 \\
\text { months }\end{array}$ & multivariate & $\begin{array}{l}\text { Age, Menopause, BMI, } \\
\text { Histology, Grade, Stage, } \\
\text { Residual disease, ER, PR, } \\
\text { AR, TNEOC expression }\end{array}$ & Platinum-based \\
\hline $\begin{array}{l}\text { Farkkila et } \\
\text { al. [67] }\end{array}$ & 2014 & Finland & single & 80 & median $52(19-87)$ & I-III & $\mathrm{IHC}$ & PFS & $\begin{array}{c}\text { mean } 16.8 \\
\text { years }\end{array}$ & multivariate & $\begin{array}{c}\text { stage, GATA4 expression, } \\
\text { nuclear atypia }\end{array}$ & Platinum-based \\
\hline Cai et al. [68] & 2015 & China & single & 95 & NR & I-IV & $\mathrm{IHC}$ & OS & NR & multivariate & $\begin{array}{l}\text { grade, histology, stage, } \\
\text { FASN expression }\end{array}$ & - \\
\hline
\end{tabular}

A.C.C, adriamycin+cyclophosphamide+Carboplatin; Ca.C, Carboplatin+cyclophosphamide; COX2,cytochrome c oxidase subunit II; ER,estrogen receptor; EGFR, epidermal growth factor receptor; FIGO, International Federation of Gynecology and Obstetrics; FASN,fatty acid synthase; FISH, fluorescence in situ hybridization; GATA4,GATA binding protein 4; IHC, Immunohistochemistry; N, no; NR, not reported; OS, overall survival; PFS, progression-free survival; P.A.C, Cisplatin+adriamycin+cyclophosphamide; P.C, Cisplatin+cyclophosphamide; P.T, Paclitaxel and cisplatin; P53,nuclear protein 53; PR, Progesterone receptor; TNEOC, triple-negative epithelial ovarian cancer; RT-PCR reverse transcription-polymerase chain reaction; Y, yes.

in EOC subjects. The conclusions were based on pooled data. The data indicated that HER-2/neu expression in EOC subjects had a significant disadvantage on OS and PFS. Concomitantly, the summary of HRs across studies calculated for each subgroup altered the OS results substantially, although the PFS in the subgroups of "North America, Asian" of "country of origin," "Others" of "survival analysis," and "Multiple" of "Centers involved" revealed no influence on the results. Finally, the results suggested that the methodology used to assess HER-2/ neu expression is considered highly significant. The majority of the meta-analysis studies used IHC staining for the detection of HER-2/neu expression. IHC is a reliable diagnostic technique due to its high sensitivity and specificity, its simplicity and cost-effectiveness. However, the results obtained by IHC are highly dependent on the storage time and fixation method of the paraffin-embedded tissues, the selection of the primary antibody and the IHC staining protocol [65]. Therefore, a subgroup analysis was constructed for the parameter detection assay (IHC vs. Others) and the results demonstrated that different assay methodologies did not change the overall survival $(\mathrm{P}=0.290)$.

The present systematic review and meta-analysis have shown that HER-2/neu expression was associated with the survival of EOC subjects. HER-2/neu expression could be used as a prognostic indicator in the majority of the subgroups examined. This finding was based on the parameters sample size, chemotherapy and WHO grade 
Table 2: Subgroup analyses and meta-regression of the relationships between HER-2 and overall survival or progression-free-survival

\begin{tabular}{|c|c|c|c|c|c|c|}
\hline \multirow{4}{*}{$\begin{array}{l}\text { Comparison } \\
\text { variables }\end{array}$} & \multirow{2}{*}{\multicolumn{3}{|c|}{$\begin{array}{c}\text { Overall survival } \\
\text { Number of studies, }\end{array}$}} & \multicolumn{3}{|c|}{ Progression-free survival } \\
\hline & & & & \multicolumn{3}{|c|}{ Number of studies, } \\
\hline & \multirow{2}{*}{$\begin{array}{c}\text { Heterogeneity } \\
\left(\mathrm{I}^{2} \text { statistics; }\right. \\
\%)\end{array}$} & \multirow{2}{*}{$\begin{array}{l}\text { HR } 95 \% C I, P \\
\text { value }\end{array}$} & \multirow{2}{*}{$\begin{array}{c}\begin{array}{c}\text { Meta- } \\
\text { regression }\end{array} \\
\text { P value }\end{array}$} & Heterogeneity & \multirow{2}{*}{$\begin{array}{l}\text { HR } 95 \% C I, P \\
\text { value } P \text { value }\end{array}$} & \multirow{2}{*}{$\begin{array}{c}\begin{array}{c}\text { Meta- } \\
\text { regression, }\end{array} \\
\text { P value }\end{array}$} \\
\hline & & & & $\begin{array}{c}\left(I^{2} \text { statistics; }\right. \\
\%)\end{array}$ & & \\
\hline Total & $49(39.8)$ & $\begin{array}{l}1.41(1.31 \text { to } \\
1.51),<0.001\end{array}$ & NA & $22(32.9)$ & $\begin{array}{l}1.38(1.23 \text { to } \\
1.56),<0.001\end{array}$ & NA \\
\hline \multicolumn{7}{|l|}{ Origin country } \\
\hline North America & $7(0)$ & $\begin{array}{l}1.74(1.41 \text { to } \\
2.17),<0.001\end{array}$ & \multirow[t]{3}{*}{0.493} & $3(17.6)$ & $\begin{array}{l}1.04(0.55 \text { to } \\
1.95), 0.525\end{array}$ & \multirow[t]{3}{*}{0.623} \\
\hline Asian & $5(0)$ & $\begin{array}{l}1.47(1.05 \text { to } \\
2.10),<0.001\end{array}$ & & $2(0)$ & $\begin{array}{l}1.01(0.47 \text { to } \\
2.17), 0.983\end{array}$ & \\
\hline Europe & $37(48.4)$ & $\begin{array}{l}1.53(1.34 \text { to } \\
1.74),<0.001\end{array}$ & & $17(37.2)$ & $\begin{array}{l}1.44(1.21 \text { to } \\
1.71),<0.001\end{array}$ & \\
\hline \multicolumn{7}{|l|}{ Sample size } \\
\hline$\geq 100$ & $24(28.3)$ & $\begin{array}{l}1.51(1.32 \text { to } \\
1.74),<0.001\end{array}$ & \multirow[t]{2}{*}{0.666} & $13(34.3)$ & $\begin{array}{l}1.39(1.12 \text { to } \\
1.72), 0.003\end{array}$ & \multirow[t]{2}{*}{0.990} \\
\hline$<100$ & $25(46.3)$ & $\begin{array}{l}1.60(1.34 \text { to } \\
1.90),<0.001\end{array}$ & & $9(37.6)$ & $\begin{array}{l}1.39(1.10 \text { to } \\
1.80), 0.016\end{array}$ & \\
\hline \multicolumn{7}{|l|}{$\begin{array}{l}\text { Median/mean } \\
\text { age y }\end{array}$} \\
\hline$\geq 55$ & $29(34.6)$ & $\begin{array}{l}1.55(1.35 \text { to } \\
1.78),<0.001\end{array}$ & \multirow[t]{3}{*}{0.823} & $16(42.4)$ & $\begin{array}{l}1.46(1.19 \text { to } \\
1.79),<0.001\end{array}$ & \multirow[t]{3}{*}{0.319} \\
\hline$<55$ & $10(43.6)$ & $\begin{array}{l}1.49(1.13 \text { to } \\
1.97), 0.005\end{array}$ & & $6(0)$ & $\begin{array}{l}1.39(1.18 \text { to } \\
1.63), 0.023\end{array}$ & \\
\hline NR & $10(2.7)$ & $\begin{array}{l}1.64(1.36 \text { to } \\
2.00),<0.001\end{array}$ & & NR & NR & \\
\hline \multicolumn{7}{|l|}{$\begin{array}{l}\text { Follow up } \\
\text { period y }\end{array}$} \\
\hline$>5$ & $13(56.6)$ & $\begin{array}{l}1.64(1.33 \text { to } \\
2.02),<0.001\end{array}$ & \multirow[t]{4}{*}{0.656} & $6(27.5)$ & $\begin{array}{l}1.78(1.41 \text { to } \\
2.25),<0.001\end{array}$ & \multirow[t]{4}{*}{0.021} \\
\hline$<5$ & $22(28.9)$ & $\begin{array}{l}1.52(1.30 \text { to } \\
1.79),<0.001\end{array}$ & & $10(0)$ & & \\
\hline NR & $14(26.3)$ & $\begin{array}{l}1.51(1.22 \text { to } \\
1.88),<0.001\end{array}$ & & $6(40.5)$ & $\begin{array}{l}1.20 .(0.98 \text { to } \\
1.47), 0.073\end{array}$ & \\
\hline & & & & & $\begin{array}{l}1.10(0.77 \text { to } \\
1.58), 0.595\end{array}$ & \\
\hline \multicolumn{7}{|l|}{ detection assay } \\
\hline $\mathrm{IHC}$ & $38(35.0)$ & $\begin{array}{l}1.60(1.41 \text { to } \\
1.83),<0.001\end{array}$ & 0.290 & $20(30.8)$ & $\begin{array}{l}1.43(1.19 \text { to } \\
1.71),<0.001\end{array}$ & \multirow[t]{2}{*}{0.411} \\
\hline Others & $11(12.7)$ & $\begin{array}{l}1.33(1.16 \text { to } \\
1.53),<0.001\end{array}$ & & $2(71.8)$ & $\begin{array}{l}1.08(0.56 \text { to } \\
2.10), 0.819\end{array}$ & \\
\hline
\end{tabular}

(Continued) 


\begin{tabular}{|c|c|c|c|c|c|c|}
\hline \multirow{4}{*}{$\begin{array}{l}\text { Comparison } \\
\text { variables }\end{array}$} & \multirow{2}{*}{\multicolumn{3}{|c|}{$\begin{array}{c}\text { Overall survival } \\
\text { Number of studies, }\end{array}$}} & \multirow{2}{*}{\multicolumn{3}{|c|}{$\begin{array}{c}\text { Progression-free survival } \\
\text { Number of studies, }\end{array}$}} \\
\hline & & & & & & \\
\hline & \multirow{2}{*}{$\begin{array}{c}\text { Heterogeneity } \\
\left(\mathrm{I}^{2} \text { statistics; }\right. \\
\%) \\
\end{array}$} & \multirow{2}{*}{$\begin{array}{l}\text { HR } 95 \% C I, P \\
\text { value }\end{array}$} & \multirow{2}{*}{$\begin{array}{c}\begin{array}{c}\text { Meta- } \\
\text { regression }\end{array} \\
\text { P value }\end{array}$} & \multirow{2}{*}{$\begin{array}{c}\text { Heterogeneity } \\
\left(\begin{array}{c}\mathrm{I}^{2} \text { statistics; } \\
\%)\end{array}\right.\end{array}$} & \multirow{2}{*}{$\begin{array}{l}\text { HR } 95 \% C I, P \\
\text { value P value }\end{array}$} & \multirow{2}{*}{$\begin{array}{c}\begin{array}{c}\text { Meta- } \\
\text { regression, }\end{array} \\
\text { P value }\end{array}$} \\
\hline & & & & & & \\
\hline \multicolumn{7}{|l|}{$\begin{array}{l}\text { Survival } \\
\text { analysis }\end{array}$} \\
\hline multivariate & $34(47.4)$ & $\begin{array}{c}1.54(1.35 \text { to } \\
1.76),<0.001\end{array}$ & \multirow[t]{2}{*}{0.871} & $16(40.2)$ & $\begin{array}{l}1.43(1.16 \text { to } \\
1.74), 0.001\end{array}$ & \multirow[t]{2}{*}{0.549} \\
\hline others & $15(3.9)$ & $\begin{array}{c}1.58(1.34 \text { to } \\
1.73),<0.001\end{array}$ & & $6(0)$ & $\begin{array}{l}1.23(0.98 \text { to } \\
1.55), 0.077\end{array}$ & \\
\hline \multicolumn{7}{|l|}{ WHO grade } \\
\hline II-IV & $15(21.2)$ & $\begin{array}{c}1.79(1.51 \text { to } \\
2.12),<0.001\end{array}$ & \multirow[t]{2}{*}{0.057} & $9(52.7)$ & $\begin{array}{l}1.49(1.16 \text { to } \\
1.90), 0.002\end{array}$ & \multirow[t]{2}{*}{0.414} \\
\hline I-IV & $34(34.3)$ & $\begin{array}{l}1.43(1.26 \text { to } \\
1.63),<0.001\end{array}$ & & $13(13.9)$ & $\begin{array}{l}1.29(1.04 \text { to } \\
1.61), 0.020\end{array}$ & \\
\hline \multicolumn{7}{|l|}{$\begin{array}{l}\text { Centers } \\
\text { involved }\end{array}$} \\
\hline Single & $36(45.5)$ & $\begin{array}{l}1.63(1.42 \text { to } \\
1.87),<0.001\end{array}$ & \multirow[t]{2}{*}{0.155} & $13(1.1)$ & $\begin{array}{l}1.38(1.20 \text { to } \\
1.60),<0.001\end{array}$ & \multirow[t]{2}{*}{0.958} \\
\hline Multiple & $13(18.7)$ & $\begin{array}{l}1.55(1.39 \text { to } \\
1.73), 0.001\end{array}$ & & $9(58.3)$ & $\begin{array}{l}1.35(0.93 \text { to } \\
1.95), 0.112\end{array}$ & \\
\hline \multicolumn{7}{|l|}{ Chemotherapy } \\
\hline Yes & $33(46.3)$ & $\begin{array}{l}1.50(1.31 \text { to } \\
1.71),<0.001\end{array}$ & 0.302 & $18(39.9)$ & $\begin{array}{l}1.33(1.12 \text { to } \\
1.59), 0.001\end{array}$ & \multirow[t]{2}{*}{0.117} \\
\hline No & $16(0)$ & $\begin{array}{c}1.72(1.46 \text { to } \\
2.03),<0.001\end{array}$ & & $4(0)$ & $\begin{array}{l}1.94(1.22 \text { to } \\
3.07), 0.005\end{array}$ & \\
\hline
\end{tabular}

CI, confidence interval; het, heterogeneity; HR, hazard ratio; NA, not available; NR, not reported.

(Table 2). The associations with OS and PFS were similar following adjustment by TFM and/or the Copas model.

In the present study, the observed heterogeneity may be attributed to the positive expression cut off values that ranged from $5 \%$ to $65 \%$ and the different IHC protocols used. Therefore, the variables IHC staining and scoring protocols have to be taken into consideration during the meta-analysis of the selected studies, due to bias originating from the expression studies of HER-2/neu. The expression of this protein varied among the 45 studies of the present analysis due to different test methods used. These included the type of the primary antibodies and the cut off values used. Thus, it is necessary to establish a uniform methodology for the evaluation of biomarkers.

The studies included and the subgroup analysis indicated the absence of heterogeneity. An additional potential source of bias is attributed to the HR method and the extrapolation of $95 \%$ CI. The failure to repeat the latter statistical results may result in additional estimation in the meta analysis by the data presented in each article. In case of the unavailability of the data, the analysis was conducted by data extrapolation from survival curves. Assumptions regarding the censoring process were carried out. The study included multivariate and univariate survival data analysis. These results were further confirmed by an adequately designed prospective study. Moreover, the prognostic merit of the HER$2 /$ neu overexpression status required determination by appropriate multivariate analysis. Several studies contributed to the observed heterogeneity in the metaanalysis of OS and PFS. TFM, the Copas model and the subgroup analyses that were conducted using certain clinical variables, yielded consistent data compared with the primary analyses, indicating the robustness of 
the data and the lack of publication bias. However, the interpretation of the results should be carried out with caution since publication bias is ubiquitous [66], and cannot be accurately determined by the use of statistical tests.

A total of 3 reviews have previously described the use of HER-2/neu expression as an indicator of the outcomes in EOC $[42,54,62]$. The initial meta-analysis study by P de Graeff et al. demonstrated that the elevated level of HER-2/neu expression was associated with worse overall survival $(\mathrm{HR}=1.41 ; 95 \% \mathrm{CI}, 1.31$ to 1.51 ), although considerable publication bias was present with regard to HER-2/neu expression [40]. The study conducted by Zhao et al. was consistent with the study by $\mathrm{P}$ de Graeff, which indicated that HER-2/neu expression was significantly associated with worse PFS and shorter OS. However, publication bias of the studies that were included in the analysis was evaluated by funnel plots and Egger's test and no significant publication bias was noted. Wang et al. investigated the data from 20 eligible

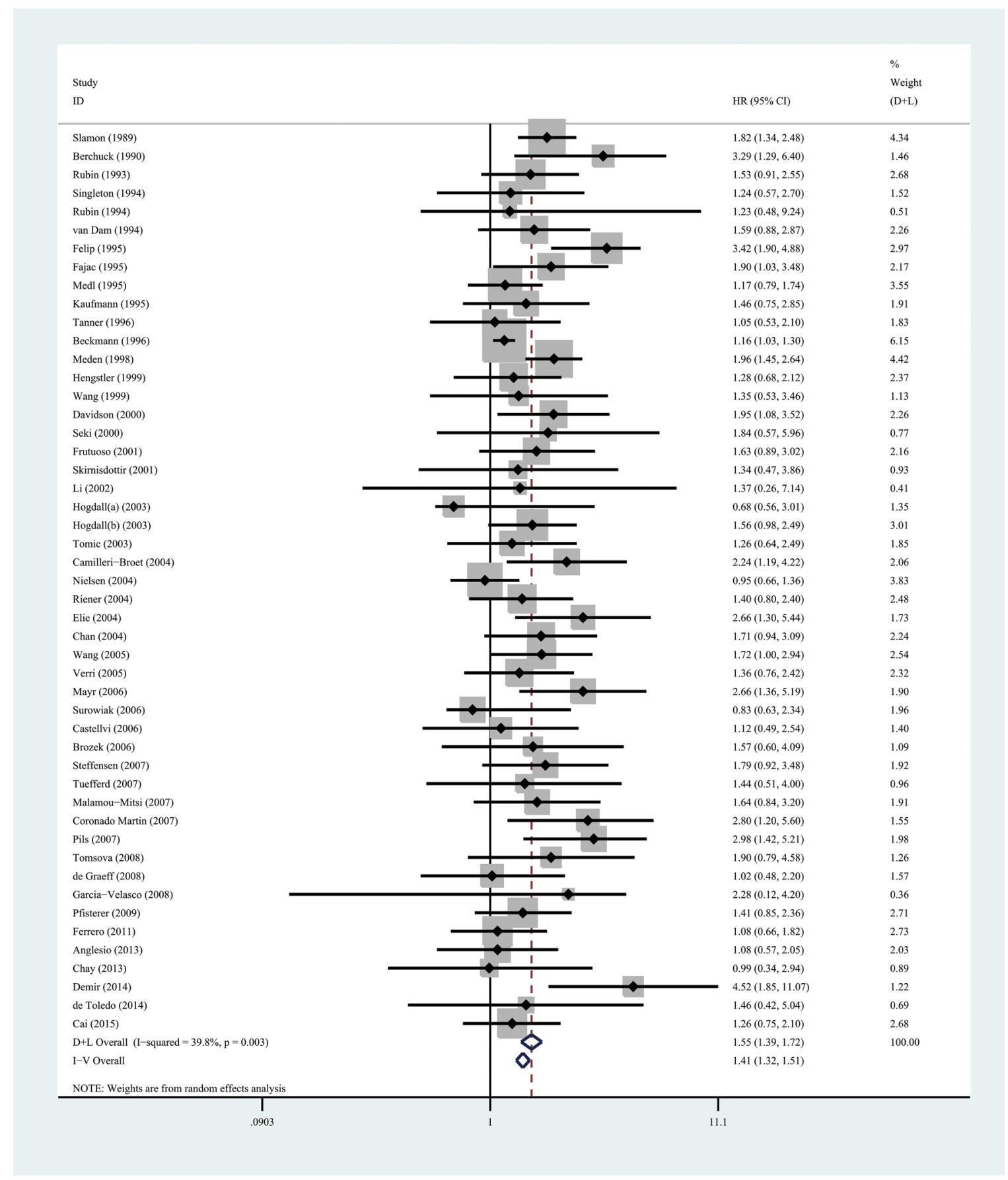

Figure 2: A forest plot of HR and 95\% CI of the association between HER-2/neu expression and OS in patients with EOC. 


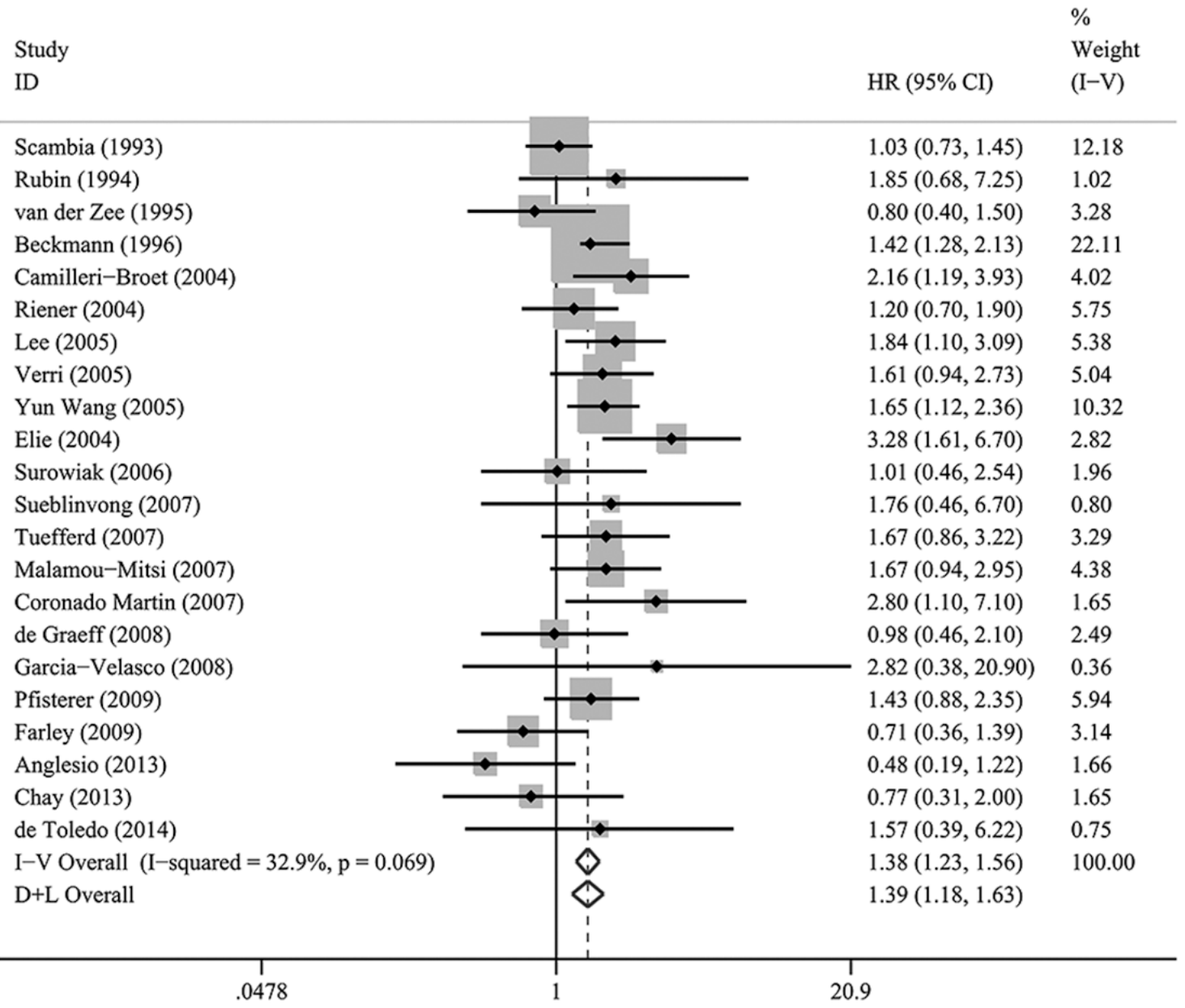

Figure 3: A forest plot of HR and 95\% CI of the association between HER-2/neu expression and PFS in patients with EOC.

A

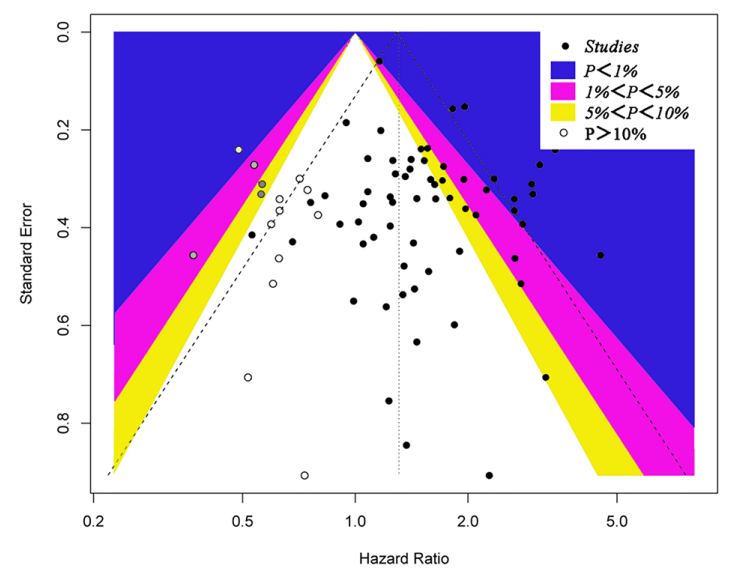

B

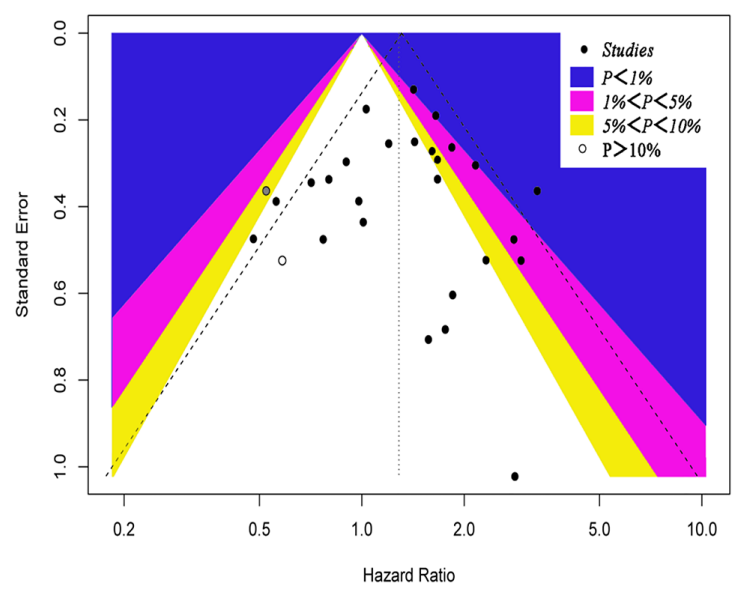

Figure 4: A contour-enhanced funnel plot for meta-analysis. (A) A contour-enhanced funnel plot for meta-analysis of the association between the HER-2/neu expression and OS in patients with EOC. The left blank area represents the area where 15 studies (white circles) were included when the trim-and-fill method was applied. (B) A contour-enhanced funnel plot for meta-analysis of the association between the HER-2/neu expression and PFS in patients with EOC. The left blank area represents the area where two studies (white circles) were included when the trim-and-fill method was applied. 
studies in order to evaluate the association of HER-2/neu overexpression and EOC subject survival. The analysis comprised 3,055 patients. Combined HRs suggested that HER-2/neu expression was not significantly associated with survival ( $\mathrm{HR}=1.05 ; 95 \% \mathrm{CI}, 0.92-1.19)$. The Begg's funnel plot and the Egger's test were conducted in order to assess the publication bias in the studies.

The present meta-analysis study provides robust statistical evidence regarding the prognosis of EOC subjects determined by HER-2/neu overexpression. Although two previous studies [54, 62] showed a prognostic association of HER-2/neu expression in patients with EOC, the statistical power was low and it was restricted to small sample sizes. The contradiction between the aforementioned studies is attributed to a variety of factors. Firstly, the significant variation in the study design was noted that was notably attributed to the patient recruitment (single center vs. multi center). In addition, certain epidemiological studies were included that used population-based EOC subjects. Secondly, a considerable variation was noted in the sample sizes among different studies. The small sample size renders the studies susceptible to publication bias. The funnel plots (Figure 4) demonstrated non-symmetrical distribution for low statistical power studies. Thirdly, certain differences in the detection assays among studies were noted. IHC was the main detection method. Moreover, the disease characteristics namely, disease stage and tumor location varied among different studies that resulted in heterogeneity with regard to the study findings. In the present study, subgroup analyses were conducted based on certain study characteristics that were found in the prognostic association of tumor HER-2/neu expression. Finally, TFM and the Copas models were applied for adjustment and no significant publication bias was noted, as demonstrated by the consistency of the results.

The present meta-analysis may have several limitations that need to be addressed. Firstly, the possibility of missing studies that are relevant to the topic cannot be avoided, particularly in studies published in languages other than English. Negative studies may exist that were never published as full-length articles, and the original data of several studies could not be obtained. Secondly, the statistical analysis exhibited low power due to the inclusion of limited number of articles $(n=56)$. The present study was based on retrospective studies rather than prospective studies, which limits the potential to effectively avoid recall and selection biases, although the results were adjusted by 2 models (TFM and Copas model). Thirdly, the risk of bias could not be adequately assessed for each publication due to lack of available data for analysis in the majority of the original reports. Moreover, the authors and/or sponsors of certain studies could be contacted for data retrieval [55]. Several HRs in the included studies were from the rough estimates of Kaplan-Meier survival curves [19-21, 25, 29, 64] and therefore the results may be inaccurate. Fourthly, the accuracy and precision of the pooled estimates could be affected by the different survival analysis method. The multivariate Cox proportional hazards model was mainly used by most studies, while a few studies failed to report the statistical model used, and a limited number of studies applied solely univariate analysis [9, 11, 16-18, 30, 31]. In addition, adjustment variables varied considerably across studies. Moreover, the majority of the HRs from the included studies were from multivariate analyses by adjustment for confounding factors. However, different confounding factors were found in different included studies. Therefore, the merged HRs exhibit a degree of heterogeneity. It is important to note that sensitivity analyses related to a patient treatment regimen and/ or detailed subgroup analyses could not be conducted according to the tumor site (left EOC or right EOC) and disease stage due to lack of available data in the studies examined. Certain factors such as the aforementioned clinicopathological parameters have been shown to be associated with both HER-2/neu expression and prognosis in EOC patients. Finally, evident heterogeneity was present for several outcomes that could not be explained substantially by the present subgroups. This limits the understanding of the association in various settings and restricts the general ability of the findings.

The present study exhibits significant advantages. A coherent, extensive, and reproducible search of the relevant studies was conducted using several online databases in the absence of limitations such as publication status that resulted in the selection of appropriate studies for this meta-analysis. Furthermore, we included a large sample size of 7,212 patients that enabled the quantitative assessment of the association of HER-2/neu expression with EOC prognosis. Moreover, the subgroup analyses were conducted according to key study characteristics namely, the country of origin, the disease stage, the detection assay, and the follow-up period. Consistent findings were obtained irrespective of the majority of the study characteristics. In addition, although subjectivity was noted in the assessment, the quality scale of the existing prognostic studies provided the rating of the scientific evidence used in the analysis. Finally, the majority of the studies revealed null association with HER-2/neu status, while others provided either negative or positive association, with HER-2/neu status indicating the uncertainty of the survival outcomes of the latter status in EOC patients. The current study minimized the selection bias by the strict pre-specification screening process that was based on the study eligibility criteria. Additionally, multiple modalities were used to evaluate the extent of publication bias.

Taken collectively, the results of the present systematic review and meta-analysis provide strong evidence of the prognostic value of HER-2/neu expression for EOC patients. The study further indicated that HER- 
2/neu is associated with lower OS and PFS. Therefore, it can be deduced that HER-2/neu targeted therapy is a promising and revolutionary strategy for cancer patients.

\section{MATERIALS AND METHODS}

\section{Search strategy and study selection}

A comprehensive search of the medical literature was conducted on studies evaluating the effect of HER2/neu expression on the survival of patients with EOC. Databases such as PubMed and Embase were searched using the terms "ovaries" or "ovary" or "ovarian", "cancer*" or "malignan*" or "tumour" or "carcinoma or neoplas*" or "tumor", "cerbB2" or "Neu" or "HER2" or "human epidermal growth factor receptor 2", and "prognos*" or "recurren*" or "death" or "predict*" or "survival". The literature search was executed in March 2016. Detailed search strategies for both databases are shown in Supplementary Appendix 1. Furthermore, references were searched manually to identify relevant studies during the screening process.

All candidate studies were reviewed by two independent reviewers (Wang $\mathrm{K}$ and Zheng LZ), and any disagreement was solved by the third investigator. The search was initially narrowed based on the title followed by the abstract, and finally full papers were reviewed if they were categorized as relevant studies. All references from review papers and original reports were examined to further identify any relevant studies. The inclusion criteria were as follows: (i) studies published as original article, regardless of the language; (ii) studies which involves EOC diagnosis by pathological examination; (iii) studies that reported the correlation of HER-2/neu expression with overall survival (OS) or progression-free survival (PFS); (iv) the papers that did not directly provide hazard ratios (HRs)/odds ratios and 95\% confidence intervals (CIs) were kept to rebuild them using the $P$ values and other data reported; (v) the most recent studies or comprehensive reports where the same group or author reported results were procured from the same EOC patient population in more than one article; (vi) studies that included more than 40 patients.

\section{Data extraction}

The final data were extracted from the included studies independently by two reviewers (Wang $\mathrm{K}$ and Zheng LZ). Data extraction of first author's name, publication year, country of the population studied, number of patients, age at the time of diagnosis (mean, median, range), WHO grade, assay method, treatment regimen, survival data including OS and PFS, time of follow-up (median, mean, minimum, and maximum), survival analysis, and adjustment variables were performed. OS was defined as the time from the medical treatment until death or last follow-up. PFS was calculated as the interval between the date of treatment and the detection of recurrence or death from any cause. Disagreements between the researchers' were resolved by discussing with a third reviewer (Zheng YQ) until a consensus was reached or by contracting experts if necessary. From studies that reported HR in both univariate and multivariate models, we extracted data from the latter because these results were more convincing, as there had been adjustment for potential confounders. The more significant HR value was extracted instead of both HR values.

\section{Quality assessment of primary studies}

Quality assessment of the included primary studies was independently performed by two reviewers (Wang $\mathrm{K}$ and Zheng LZ) using the Newcastle-Ottawa Scale (NOS) [13]. Studies with NOS score $\geq 6$ were considered high quality research. Any disagreement was solved by discussion.

\section{Statistical analysis}

The Stata 12.0 statistical software (Stata Corporation, TX, USA) was used to perform metaanalysis. HR and $95 \%$ CI were estimated directly from each study or from an estimation of the Kaplan-Meier survival curves using the methods by Parmar et al [67]. A $\mathrm{HR}$ value $<1$ indicated a better prognosis in patients with EOC and HER-2/neu expression, whereas HR value $>1$ implied a poor prognosis. If several HR estimates were presented in the same study, only the most powerful ones (multivariate analysis was chosen over univariate analysis, and univariate analysis was chosen over unadjusted Kaplan-Meier analysis) were chosen.

This study investigated the between-study heterogeneity using the Cochran's Q-test and $I^{2}$ statistics, and a $P$ value for heterogeneity by $I^{2}$ value $\geq 50 \%$ suggested substantial heterogeneity. The random-effects model, which is generally more conservative was chosen. Also, subgroup analyses were performed to investigate the potential causes of heterogeneity according to study origin, sample size, follow-up period, patient's age, detection assay, survival analysis, WHO grade and chemotherapy regimen.

The evidence of publication bias was assessed by the visual judgment of the contour-enhanced funnel plot symmetry as well as by Begg's regression and Egger's linear regression methods $[68,69]$. Duval's nonparametric trim-and-fill procedure was applied to assess the possible effect of publication bias [70]. Moreover, the Copas model was used to conduct sensitivity analysis by considering both the effect size and sample size [71]. All statistical tests were two sided, and a $P$ value of $<0.05$ was considered to be statistically significant. 


\section{Abbreviations}

Epithelial ovarian cancer (EOC); overall survival (OS); progression-free survival (PFS); Hazard ratios (HRs); confidence interval (CI); World Health Organization (WHO); human epidermal growth factor receptor 2 (HER-2/neu); fluorescence in situ hybridization (FISH); enzyme-linked immuno sorbent assay (ELISA).

\section{Author contributions}

$\mathrm{KW}, \mathrm{CG}$ and JW analyzed the data and wrote the manuscript. XJ and LX searched and collected the literatures. YZ, LX, and LZ participated in the discussion and designed the study. All authors read and approved the final manuscript.

\section{CONFLICTS OF INTEREST} interests.

The authors declare that they have no competing

\section{FUNDING}

This study was supported by grants from the Natural Science Foundation of China (No. 81502147, Liang Xia).

\section{REFERENCES}

1. Siegel R, Ma J, Zou Z, Jemal A. Cancer statistics, 2014. CA Cancer J Clin. 2014; 64:9-29.

2. Jemal A, Siegel R, Xu J, Ward E. Cancer statistics, 2010. CA Cancer J Clin. 2010; 60:277-300.

3. Ozols RF. Treatment goals in ovarian cancer. Int J Gynecol Cancer. 2005; 15:3-11.

4. Winter WE 3rd, Maxwell GL, Tian C, Carlson JW, Ozols RF, Rose PG, Markman M, Armstrong DK, Muggia F, McGuire WP. Prognostic factors for stage III epithelial ovarian cancer: a Gynecologic Oncology Group Study. J Clin Oncol. 2007; 25:3621-3627.

5. Morgan RJ Jr, Armstrong DK, Alvarez RD, Bakkum-Gamez JN, Behbakht K, Chen LM, Copeland L, Crispens MA, DeRosa M, Dorigo O, Gershenson DM, Gray HJ, Hakam A, et al. Ovarian Cancer, Version 1.2016, NCCN Clinical Practice Guidelines in Oncology. J Natl Compr Canc Netw. 2016; 14:1134-1163.

6. Cramer DW, Bast RC Jr, Berg CD, Diamandis EP, Godwin AK, Hartge P, Lokshin AE, Lu KH, McIntosh MW, Mor G, Patriotis C, Pinsky PF, Thornquist MD, et al. Ovarian cancer biomarker performance in prostate, lung, colorectal, and ovarian cancer screening trial specimens. Cancer Prev Res (Phila). 2011; 4:365-374

7. Saxena R, Dwivedi A. ErbB family receptor inhibitors as therapeutic agents in breast cancer: current status and future clinical perspective. Med Res Rev. 2012; 32:166-215.
8. Slamon DJ, Godolphin W, Jones LA, Holt JA, Wong SG, Keith DE, Levin WJ, Stuart SG, Udove J, Ullrich A, et al. Studies of the HER-2/neu proto-oncogene in human breast and ovarian cancer. Science. 1989; 244:707-712.

9. Berchuck A, Kamel A, Whitaker R, Kerns B, Olt G, Kinney R, Soper JT, Dodge R, Clarke-Pearson DL, Marks P, McKenzie S, Yin S, Bast RC Jr. Overexpression of HER-2/ neu is associated with poor survival in advanced epithelial ovarian cancer. Cancer Res. 1990; 50:4087-4091.

10. Felip E, Encabo G, Vidal MT, Vera R, del Campo JM, Rubio D. [C-erbB-2 protein in ovarian epithelial cancer: correlation between expression in tumor tissue and blood levels]. [Article in Spanish]. Med Clin (Barc). 1995; 105:5-8.

11. Meden H, Marx D, Roegglen T, Schauer A, Kuhn W. Overexpression of the oncogene c-erbB-2 (HER2/neu) and response to chemotherapy in patients with ovarian cancer. Int J Gynecol Pathol. 1998; 17:61-65.

12. Davidson B, Gotlieb WH, Ben-Baruch G, Nesland JM, Bryne M, Goldberg I, Kopolovic J, Berner A. E-Cadherin complex protein expression and survival in ovarian carcinoma. Gynecol Oncol. 2000; 79:362-371.

13. Elie C, Geay JF, Morcos M, Le Tourneau A, Girre V, Broet P, Marmey B, Chauvenet L, Audouin J, Pujade-Lauraine E, Camilleri-Broet S. Lack of relationship between EGFR-1 immunohistochemical expression and prognosis in a multicentre clinical trial of 93 patients with advanced primary ovarian epithelial cancer (GINECO group). Br J Cancer. 2004; 91:470-475.

14. Mayr D, Kanitz V, Amann G, Engel J, Burges A, Lohrs U, Diebold J. HER-2/neu gene amplification in ovarian tumours: a comprehensive immunohistochemical and FISH analysis on tissue microarrays. Histopathology. 2006; 48:149-156.

15. Rubin SC, Finstad CL, Wong GY, Almadrones L, Plante M, Lloyd KO. Prognostic significance of HER-2/ neu expression in advanced epithelial ovarian cancer: a multivariate analysis. Am J Obstet Gynecol. 1993; 168:162-169.

16. Scambia G, Benedetti Panici P, Ferrandina G, Battaglia F, Baiocchi G, Di Stefano P, Tinari N, Coronetta F, Piantelli M, Natali P, Iacobelli S, Mancuso S. Expression of HER-2/neu oncoprotein, DNA-ploidy and S-phase fraction in advanced ovarian cancer. Int J Gynecol Cancer. 1993; 3:271-278.

17. Singleton TP, Perrone T, Oakley G, Niehans GA, Carson L, Cha SS, Strickler JG. Activation of c-erbB-2 and prognosis in ovarian carcinoma. Comparison with histologic type, grade, and stage. Cancer. 1994; 73:1460-1466.

18. Rubin SC, Finstad CL, Federici MG, Scheiner L, Lloyd KO, Hoskins WJ. Prevalence and significance of HER-2/ neu expression in early epithelial ovarian cancer. Cancer. 1994; 73:1456-1459.

19. van Dam PA, Vergote IB, Lowe DG, Watson JV, van Damme P, van der Auwera JC, Shepherd JH. Expression of 
c-erbB-2, c-myc, and c-ras oncoproteins, insulin-like growth factor receptor I, and epidermal growth factor receptor in ovarian carcinoma. J Clin Pathol. 1994; 47:914-919.

20. Felip E, Del Campo JM, Rubio D, Vidal MT, Colomer R, Bermejo B. Overexpression of c-erbB-2 in epithelial ovarian cancer. Prognostic value and relationship with response to chemotherapy. Cancer. 1995; 75:2147-2152.

21. Fajac A, Benard J, Lhomme C, Rey A, Duvillard P, Rochard F, Bernaudin JF, Riou G. c-erbB2 gene amplification and protein expression in ovarian epithelial tumors: evaluation of their respective prognostic significance by multivariate analysis. Int J Cancer. 1995; 64:146-151.

22. Medl M, Sevelda P, Czerwenka K, Dobianer K, Hanak H, Hruza C, Klein M, Leodolter S, Mullauer-Ertl S, Rosen A, Salzer H, Vavra N, Spona J. DNA amplification of HER-2/ neu and INT-2 oncogenes in epithelial ovarian cancer. Gynecol Oncol. 1995; 59:321-326.

23. Kaufmann M, Von Minckwitz G, Kuhn W, Schmid H, Costa S, Goerttler K, Bastert G. Combination of new biologic parameters as a prognostic index in epithelial ovarian carcinoma. Int J Gynecol Cancer. 1995; 5:49-55.

24. van der Zee AG, Hollema H, Suurmeijer AJ, Krans M, Sluiter WJ, Willemse PH, Aalders JG, de Vries EG. Value of P-glycoprotein, glutathione S-transferase pi, c-erbB-2, and $\mathrm{p} 53$ as prognostic factors in ovarian carcinomas. J Clin Oncol. 1995; 13:70-78.

25. Tanner B, Kreutz E, Weikel W, Meinert R, Oesch F, Knapstein PG, Becker R. Prognostic significance of c-erB-2 mRNA in ovarian carcinoma. Gynecol Oncol. 1996; 62:268-277.

26. Beckmann R, Gyra H, Cussler K. Determination of protective erysipelas antibodies in pig and mouse sera as possible alternatives to the animal challenge models currently used for potency tests. Dev Biol Stand. 1996; 86:326.

27. Hengstler JG, Lange J, Kett A, Dornhofer N, Meinert R, Arand M, Knapstein PG, Becker R, Oesch F, Tanner B. Contribution of c-erbB-2 and topoisomerase IIalpha to chemoresistance in ovarian cancer. Cancer Res. 1999; 59:3206-3214.

28. Wang ZR, Liu W, Smith ST, Parrish RS, Young SR. c-myc and chromosome 8 centromere studies of ovarian cancer by interphase FISH. Exp Mol Pathol. 1999; 66:140-148.

29. Seki A, Yoshinouchi M, Seki N, Kodama J, Miyagi Y, Kudo T. Detection of c-erbB-2 and FGF-3 (INT-2) gene amplification in epithelial ovarian cancer. Int J Oncol. 2000; 17:103-106.

30. Frutuoso C, Silva MR, Amaral N, Martins I, De Oliveira C, De Oliveira HM. [Prognosis value of p53, C-erB-2 and Ki67 proteins in ovarian carcinoma]. [Article in Portuguese]. Acta Med Port. 2001; 14:277-283.

31. Skirnisdottir I, Sorbe B, Seidal T. The growth factor receptors HER-2/neu and EGFR, their relationship, and their effects on the prognosis in early stage (FIGO I-II) epithelial ovarian carcinoma. Int J Gynecol Cancer. 2001; 11:119-129.

32. Li H, Lee TH, Avraham H. A novel tricomplex of BRCA1, Nmi, and c-Myc inhibits c-Myc-induced human telomerase reverse transcriptase gene (hTERT) promoter activity in breast cancer. J Biol Chem. 2002; 277:20965-20973.

33. Hogdall EV, Christensen L, Kjaer SK, Blaakaer J, Bock JE, Glud E, Norgaard-Pedersen B, Hogdall CK. Distribution of HER-2 overexpression in ovarian carcinoma tissue and its prognostic value in patients with ovarian carcinoma: from the Danish MALOVA Ovarian Cancer Study. Cancer. 2003; 98:66-73.

34. Tomic S, Ilic Forko J, Babic D, Sundov D, Kuret S, Andelinovic S. c-erbB-2, p53, and nm23 proteins as prognostic factors in patients with epithelial ovarian carcinoma. Croat Med J. 2003; 44:429-434.

35. Camilleri-Broet S, Hardy-Bessard AC, Le Tourneau A, Paraiso D, Levrel O, Leduc B, Bain S, Orfeuvre H, Audouin J, Pujade-Lauraine E. HER-2 overexpression is an independent marker of poor prognosis of advanced primary ovarian carcinoma: a multicenter study of the GINECO group. Ann Oncol. 2004; 15:104-112.

36. Nielsen JS, Jakobsen E, Holund B, Bertelsen K, Jakobsen A. Prognostic significance of p53, Her-2, and EGFR overexpression in borderline and epithelial ovarian cancer. Int J Gynecol Cancer. 2004; 14:1086-1096.

37. Riener EK, Arnold N, Kommoss F, Lauinger S, Pfisterer J. The prognostic and predictive value of immunohistochemically detected HER-2/neu overexpression in 361 patients with ovarian cancer: a multicenter study. Gynecol Oncol. 2004; 95:89-94.

38. Tanabe H, Nishii H, Sakata A, Suzuki K, Mori Y, Shinozaki H, Watanabe A, Ochiai K, Yasuda M, Tanaka T. Overexpression of HER-2/neu is not a risk factor in ovarian clear cell adenocarcinoma. Gynecol Oncol. 2004; 94:735-739.

39. Chan JK, Loizzi V, Magistris A, Lin F, Rutgers J, Osann K, Disaia PJ, Berman ML. Differences in prognostic molecular markers between women over and under 45 years of age with advanced ovarian cancer. Clin Cancer Res. 2004; 10:8538-8543.

40. Lee CH, Huntsman DG, Cheang MC, Parker RL, Brown L, Hoskins P, Miller D, Gilks CB. Assessment of Her-1, Her-2, And Her-3 expression and Her-2 amplification in advanced stage ovarian carcinoma. Int J Gynecol Pathol. 2005; 24:147-152.

41. Verri E, Guglielmini P, Puntoni M, Perdelli L, Papadia A, Lorenzi P, Rubagotti A, Ragni N, Boccardo F. HER2/neu oncoprotein overexpression in epithelial ovarian cancer: evaluation of its prevalence and prognostic significance. Clinical study. Oncology. 2005; 68:154-161.

42. Wang Y, Helland A, Holm R, Kristensen GB, Borresen-Dale AL. PIK3CA mutations in advanced ovarian carcinomas. Hum Mutat. 2005; 25:322. 
43. Surowiak P, Materna V, Kaplenko I, Spaczynski M, Dietel M, Lage H, Zabel M. Topoisomerase 1A, HER/2neu and Ki67 expression in paired primary and relapse ovarian cancer tissue samples. Histol Histopathol. 2006; 21:713-720.

44. Castellvi J, Garcia A, Rojo F, Ruiz-Marcellan C, Gil A, Baselga J, Ramon y Cajal S. Phosphorylated 4E binding protein 1: a hallmark of cell signaling that correlates with survival in ovarian cancer. Cancer. 2006; 107:1801-1811.

45. Brozek I, Kardas I, Ochman K, Debniak J, Stukan M, Ratajska M, Morzuch L, Emerich J, Limon J. HER2 Amplification Has no Prognostic Value in Sporadic and Hereditary Ovarian Tumours. Hered Cancer Clin Pract. 2006; 4:39-42.

46. Steffensen KD, Waldstrom M, Jeppesen U, Jakobsen E, Brandslund I, Jakobsen A. The prognostic importance of cyclooxygenase 2 and HER2 expression in epithelial ovarian cancer. Int J Gynecol Cancer. 2007; 17:798-807.

47. Sueblinvong T, Manchana T, Khemapech N, Triratanachat $\mathrm{S}$, Termrungruanglert W, Tresukosol D. Lack of prognostic significance of HER-2/neu in early epithelial ovarian cancer. Asian Pac J Cancer Prev. 2007; 8:502-506.

48. Tuefferd M, Couturier J, Penault-Llorca F, Vincent-Salomon A, Broet P, Guastalla JP, Allouache D, Combe M, Weber B, Pujade-Lauraine E, Camilleri-Broet S. HER2 status in ovarian carcinomas: a multicenter GINECO study of 320 patients. PLoS One. 2007; 2:e1138.

49. Sasaki N, Kudoh K, Kita T, Tsuda H, Furuya K, Kikuchi Y. Effect of HER-2/neu overexpression on chemoresistance and prognosis in ovarian carcinoma. J Obstet Gynaecol Res. 2007; 33:17-23

50. Malamou-Mitsi V, Crikoni O, Timotheadou E, Aravantinos G, Vrettou E, Agnantis N, Fountzilas G. Prognostic significance of HER-2, p53 and Bcl-2 in patients with epithelial ovarian cancer. Anticancer Res. 2007; 27:1157-1165.

51. Coronado Martin PJ, Fasero Laiz M, Garcia Santos J, Ramirez Mena M, Vidart Aragon JA. [Overexpression and prognostic value of $\mathrm{p} 53$ and HER2/neu proteins in benign ovarian tissue and in ovarian cancer]. [Article in Spanish]. Med Clin (Barc). 2007; 128:1-6.

52. Pils D, Pinter A, Reibenwein J, Alfanz A, Horak P, Schmid BC, Hefler L, Horvat R, Reinthaller A, Zeillinger R, Krainer $M$. In ovarian cancer the prognostic influence of HER2/neu is not dependent on the CXCR4/SDF-1 signalling pathway. Br J Cancer. 2007; 96:485-491.

53. Tomsova M, Melichar B, Sedlakova I, Steiner I. Prognostic significance of CD3+ tumor-infiltrating lymphocytes in ovarian carcinoma. Gynecol Oncol. 2008; 108:415-420.

54. de Graeff P, Crijns AP, Ten Hoor KA, Klip HG, Hollema H, Oien K, Bartlett JM, Wisman GB, de Bock GH, de Vries EG, de Jong S, van der Zee AG. The ErbB signalling pathway: protein expression and prognostic value in epithelial ovarian cancer. Br J Cancer. 2008; 99:341-349.
55. Garcia-Velasco A, Mendiola C, Sanchez-Munoz A, Ballestin C, Colomer R, Cortes-Funes H. Prognostic value of hormonal receptors, p53, ki67 and HER2/neu expression in epithelial ovarian carcinoma. Clin Transl Oncol. 2008; 10:367-371.

56. Pfisterer J, Du Bois A, Bentz EK, Kommoss F, Harter P, Huober J, Schmalfeldt B, Burchardi N, Arnold N, Hilpert F. Prognostic value of human epidermal growth factor receptor 2 (Her-2)/neu in patients with advanced ovarian cancer treated with platinum/paclitaxel as first-line chemotherapy: a retrospective evaluation of the AGO-OVAR 3 Trial by the AGO OVAR Germany. Int J Gynecol Cancer. 2009; 19:109-115.

57. Farley J, Fuchiuji S, Darcy KM, Tian C, Hoskins WJ, McGuire WP, Hanjani P, Warshal D, Greer BE, Belinson J, Birrer MJ. Associations between ERBB2 amplification and progression-free survival and overall survival in advanced stage, suboptimally-resected epithelial ovarian cancers: a Gynecologic Oncology Group Study. Gynecol Oncol. 2009; 113:341-347.

58. Ferrero A, Dompe D, Ravarino N, Ramella A, Fuso L, Maggiorotto F, Tripodi E, Zola P. Angiogenesis and molecular markers in advanced epithelial ovarian cancer: a retrospective study. Gynecol Oncol. 2011; 123:301-307.

59. Anglesio MS, Kommoss S, Tolcher MC, Clarke B, Galletta L, Porter H, Damaraju S, Fereday S, Winterhoff BJ, Kalloger SE, Senz J, Yang W, Steed H, et al. Molecular characterization of mucinous ovarian tumours supports a stratified treatment approach with HER2 targeting in 19\% of carcinomas. J Pathol. 2013; 229:111-120.

60. Chay WY, Chew SH, Ong WS, Busmanis I, Li X, Thung S, Ngo L, Lim SL, Lim YK, Chia YN, Koh E, Pang C, Soh LT, et al. HER2 amplification and clinicopathological characteristics in a large Asian cohort of rare mucinous ovarian cancer. PLoS One. 2013; 8:e61565.

61. Demir L, Yigit S, Sadullahoglu C, Akyol M, Cokmert S, Kucukzeybek Y, Alacacioglu A, Cakalagaoglu F, Tarhan MO. Hormone receptor, HER2/NEU and EGFR expression in ovarian carcinoma--is here a prognostic phenotype? Asian Pac J Cancer Prev. 2014; 15:9739-9745.

62. de Toledo MC, Sarian LO, Sallum LF, Andrade LL, Vassallo J, de Paiva Silva GR, Pinto GA, Soares FA, Fonseca CD, Derchain SF. Analysis of the contribution of immunologically-detectable HER2, steroid receptors and of the "triple-negative" tumor status to disease-free and overall survival of women with epithelial ovarian cancer. Acta Histochem. 2014; 116:440-447.

63. Farkkila A, Andersson $\mathrm{N}$, Butzow $\mathrm{R}$, Leminen A, Heikinheimo M, Anttonen M, Unkila-Kallio L. HER2 and GATA4 are new prognostic factors for early-stage ovarian granulosa cell tumor-a long-term follow-up study. Cancer Med. 2014; 3:526-536.

64. Cai Y, Wang J, Zhang L, Wu D, Yu D, Tian X, Liu J, Jiang X, Shen Y, Zhang L, Ren M, Huang P. Expressions of fatty 
acid synthase and HER2 are correlated with poor prognosis of ovarian cancer. Med Oncol. 2015; 32:391.

65. Hall J, Paul J, Brown R. Critical evaluation of p53 as a prognostic marker in ovarian cancer. Expert Rev Mol Med. 2004; 6:1-20.

66. Ioannidis JP. How to make more published research true. PLoS Med. 2014; 11:e1001747.

67. Parmar MK, Torri V, Stewart L. Extracting summary statistics to perform meta-analyses of the published literature for survival endpoints. Stat Med. 1998; 17:2815-2834.
68. Begg CB, Mazumdar M. Operating characteristics of a rank correlation test for publication bias. Biometrics. 1994; 50:1088-1101.

69. Egger M, Davey Smith G, Schneider M, Minder C. Bias in meta-analysis detected by a simple, graphical test. BMJ. 1997; 315:629-634.

70. Duval S, Tweedie R. Trim and fill: A simple funnel-plotbased method of testing and adjusting for publication bias in meta-analysis. Biometrics. 2000; 56:455-463.

71. Jin ZC, Zhou XH, He J. Statistical methods for dealing with publication bias in meta-analysis. Stat Med. 2015; 34:343-360. 